\title{
The Contemporary Vision of Universal Strategic Planning for Facing (COVID-19) Crisis in the Field of Higher Education Via Virtual Learning \& Training
}

\author{
Dina Ali Mohamed El-Besomey \\ PhD, Advertisement \& Print \& Publication \\ Department, Applied Faculty, Benha University
}

\begin{abstract}
This is an analytical study for Global Education vision (2030 -2020) of The contemporary vision of Global strategic plan for facing (covid-19)or the renew corona disease crisis via virtual learning \& training for higher education. The research builds in the virtual university configuring its concept and how could it simulate the environments of reality, and its tools with a new contemporary vision for facing (covid-19) crisis via Global strategic plan of virtual learning \& training for higher education, and deals with virtual reality as an effective way to simulate reality whatever the circumstances and difficulties in the environment of university, through which it can be configured for different environments tell the reality of an individual can't be accessed or coexistence with them. For example, the environment of space can't be educated to student in the university environment to live by realistic, and here comes the role of virtual reality in an environment similar to the environment of space and enables the student to interact with it as if in the real environment.
\end{abstract}

Keywords: the contemporary vision (2020-2030), universal strategic plan, (Covid19) crisis, higher education, virtual learning, virtual training

\section{Introduction}

\section{The research plan}

\section{The importance of research}

The research has clear global strategy plan for facing (covid-19) or the renew corona disease crisis with both virtual education and training, where e-training will revolutionize the training sooner or later, whether we like it or not, and this fact that will certainly happen in every classroom in all the world. The electronic training will be the next generation in the visual training assistance. It will grow to become the largest of advanced wireless Communications programs. This research also deals 
with the most important benefits of virtual education and what distinguishes it from traditional education.

\section{The aim of research}

This research introduces a contemporary vision of universal strategic plan for facing (COVID-19) or the renew corona disease crisis in the field of higher education via virtual learning \& training.

This is An analytical study for Global Education vision 2020 - 2030).The research has clear global strategy plan with its steps and terminology for facing (covid-19) crisis to overcome the obstacles of the impossibility of the presence of both the teacher and the student in one place. So it comes the role of both virtual education and training, where e-training will revolutionize the training sooner or later, whether we like it or not, and this fact that will certain happen in every classroom in all the world. Both are methods of education technology.

This research also deals with the most advanced education technology, as: hologram and virtual \& argument reality and what distinguishes these educational technology tools from traditional education. So this strategy plan isn't only introduce a solution for the immerging case of (COVID-19) or the renew corona disease but also it push the education process to get progress and developed with the rapid development of virtual technology which become used in different fields and to simulate these fields' environments virtually as realistic in the education process.

The research problem this research and the challenges faced by virtual Education

The difficulty \& resistance of teachers 'accepting deals with technical and educational change in the university education level

The legal, administrative and technical barriers.as Students' resistance actively takes responsibility for the learning process, Legal, administrative and technical challenges

The resistance of students to work without a "teacher" in front of them. It is necessary to recognize that, most of our students generally have become lazier. There are many factors that play an important role, like:

1. Lack of motivation of teachers to know turns, and moves to students.

2. The absence of social idealism made from the study effort a lofty goal

3. Cultural work faces mental resistance.

4. All of this must take in consideration the methodology.

5. When the student notes that he must move from its negative position, preferred to start a protest, and attacks: the teacher, the classroom, and even 
the school or university, telling everyone that he will leave the educational institution. This feature exists mainly in the private sector, and in the face of an economic crisis, forcing some institutions to surrender in their efforts to promote the knowledge of the assets of active education, without realizing the damage, and without seeing the results of the community, who will receive a graduate of the University isn't qualified by itself. For this particular case, the policy requires the promotion of the assets of the active education for the first semester, because it is necessary to start the entire process of adjustment that replaces the assets of the passive former science to active pedagogy science that promotes a passion for knowledge and isn't boring to learn.

\section{Time limits:}

The near future (one decade=10years) of the period2020-2030

\section{Spatial borders:}

The Arab Republic of Egypt in all governmental, private and international universities\& universal universities, as: American \& European universities especially Cambridge universities.

Introduction computer simulations is used in educational purposes for many years even before small computers, and then in the late of seventies and eighties this kind of simulation becomes common in classrooms and laboratories computer in Western countries, it ranged in complexity from simple simulation to play a coin in order to learn the binary possibilities distribution. for example, the creation of (ecosystem)shaped lake in which a various animal organisms interacts, and these types of simulation were introduced textually or digitally, while the development of hardware and its potentials, the programs have been developed to introduce pictorial output.

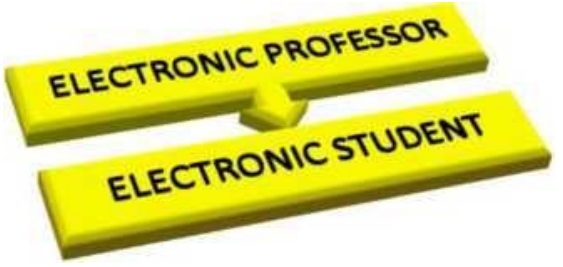

If we accept that the three-dimensional drawing and based on the screen is a form of virtual reality, it can be said that the virtual reality has been used for a period in education, and one of examples can be seen in the work of (Veronica Pantelidis) And (Lawrence Auld), who are the co-directors of the virtual reality education laboratory(VREL), in the East of Carolina University, in which a package of programs ,called Virtues VR are been used by primary school children to form the inner parts of a room or building, including using the design of walls, doors, windows, furniture and then put it in the right place in the building based on the screenbased Construction, and this activity aims to improve children's abilities to imagine the space and the 
three-dimensional place, providing fun, and give the meaning for children understanding while they were learning.

"Another example of the current use of virtual reality in education is found in Jason Project by which school children can be tested both exist in the 'Tele-presence' (which refers to the sense of presence in another place than the real place where the person is existed in it ) and 'Teleoperation 'which means the tool control in operations remotely). this program has been designed, which is supervised by the USA space agency (NASA), and began in 1989, to create excitement and motivation of children to study science, mathematics, and technology, that allows children to control by the presence in 'Tele-operation 'of vehicle under water (TROV), exploring the ocean depths, while they are watching the results of their work in the Real-Time Results on large video screens.

There is also an increase in the number of uses of the virtual reality in higher education, for examples include Learning Sites Project, which works through a team of archaeologists and experts in virtual reality, and three-dimensional models, for the instruction of graphics and audio databases, through which users explore a number of archaeological sites (in Turkey and Egypt, for example), they allow him interaction with the virtual versions of the sites that have been created with accurate translation of recorded data about the real sites, and how to report this interaction, for example; If a user gets the attention to a dark corner of the site existing in the virtual environment, he can focus on this area and explores it with greater details.

Before analyzing this contemporary vision of strategy plan .we should study the education process. We mean here the integration interactive relationship between professor and his students virtually or presently which contained from university - faculties or colleges- specialization departments- education staff - students - administrative $\&$ artificial corps - university study contents)

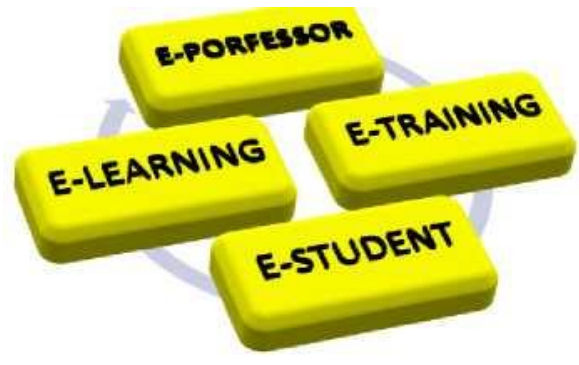

So there is three kinds of students in the education process ,including: the visual student, the listening student, and the visual \& listening student. They are in the education process has three terminologies.

The visual student in the education process are watching, thinking, and realizing The listening student in the education process are watching, thinking, and realizing 
The visual \& listening l student in the education process are watching, thinking, and realizing.

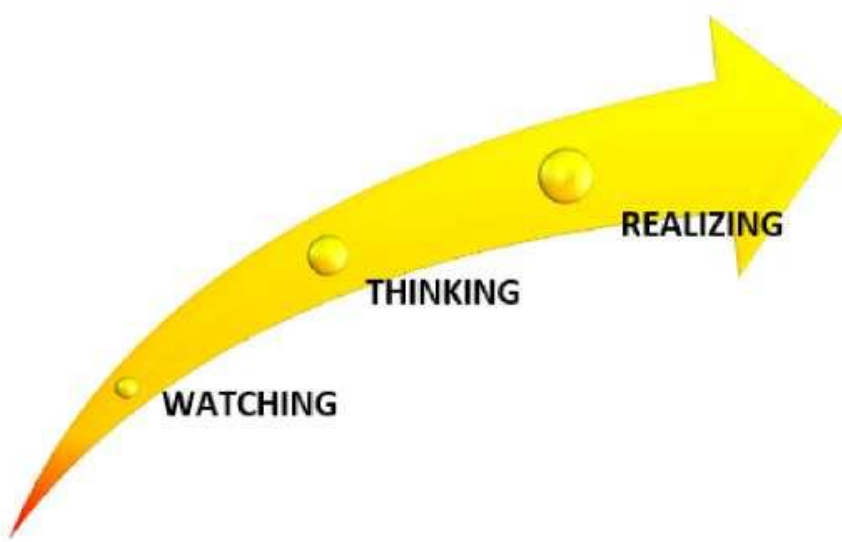

This strategy plan with its steps and terminology for facing (covid-19) crisis to overcome the obstacles of the impossibility of the presence of both the teacher and the student in one place. So it comes the role of both virtual education and training, where e-training will revolutionize the training sooner or later, whether we like it or not, and this fact that will certain happen in every classroom in all the world. Both are methods of education technology. This is contemporary vision introduced three new concepts related with the virtual education process via both E-Learning and E- Training .those concepts are E-Professor, E-Student, and E-Virtual Education Platform.

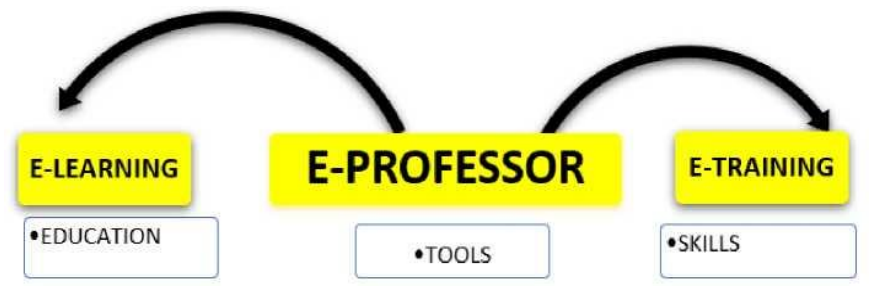

A graph describes the role of E- Professor between both E-Learning \& E-Training Processes

In this strategy we use the electronic learning \& training both side by side to get the integration of the education process. Indeed we didn't use both e-learning \& etraining only in the case that the teacher and the student aren't in one place. But also if they are in one place we can use those methods of education technology to get more interaction with the virtual environment which is generated to get full / semi /or none immersion for the student in education processes with remoting and direction of this virtual education environment via the teacher. 
This research also deals with the most advanced education technology, as: hologram and virtual\& argument reality and what distinguishes these educational technology tools from traditional education. So this strategy plan isn't only introduce a solution for the immerging case of (COVID-19) or the renew corona disease but also it push the education process to get progress and developed with the rapid development of virtual technology which become used in different fields and to simulate these fields' environments virtually as realistic in the education process.

(sherry aazlnger) confirms that virtual reality can offer the necessary tools to visualize and form abstract information to make it understanding easily. As It enriches the educational process with expertise and modern technological capabilities.Training of learners to acquire technical skills and things that are difficult to train them in reality.Submission of a virtual environment to sail through a threedimensional space. Also It enhances hologram's photos with sensory management of depth and the vacuum dimensions and The virtual environment achieves the safety for her user when studying serious or difficult information to obtain it in time and place.

As This is the universal strategy plan for facing (COVID-19) crisis in the field of higher education via virtual learning \& training. It is analytically graphed current study Global Education vision and for the near future . it is drawn as the contemporary vision with these steps2020 - 2030 ),including the following steps:Installing virtual \& argument \& hologram Interactive dynamic university education platform

Designing and developing electronic university study content, like: E-books - Especialization magazines and journals-PDF published papers- electronic encyclopedias - power points), which could be consider as some professors' tools

E-learning education installing for developing the process of education

E-training education installing for developing the skills of students and get integration with education process

University electronic portal

University server connected to professor's educational server for education purpose virtual \& argument \& hologram Interactive dynamic educational systems with his tools , and applications and software programs

simulating \& developing virtual \& argument \& hologram Interactive dynamic educational video games environments

Generating \&developing virtual \& argument \& hologram Interactive dynamic education environments' systems.

We can classify and virtual experiments and applications that have been used for education according to the following categories: 
Virtual educational games

Virtual theater

Virtual lab

Virtual museum

Virtual educational environments (Virtual classrooms, training rooms, and science workshops, libraries, virtual universities, and scientific conferences)

Virtual garden.

Virtual space and aviation

Virtual factory and Virtual vocational training institutes.

Virtual Courts \& virtual crimes.

Virtual medical operations

designing \&developing virtual \& argument \& hologram Interactive dynamic education applications for mobiles and others boarder receiver devices

Designing\& developing virtual \& argument \& hologram Interactive dynamic education software(programs)

creation \& innovation developing virtual \& argument \& hologram Interactive dynamic education hardware(devices)

\section{Virtual Reality Devices and tools:}

Devices that are worn on the head (HMD): They are similar to the mask or helmet and they consist inside of screen or two screens small to display single views or hear influential voices (stereo) and the individual can see what is offered by the program through the mask or helmet, and he can watch the object with its three dimensions or it may be covered the full of head as he can watch and listen at the same time.

Tactile gloves: A sense of devices covering all the hand and generating an active interaction between the user and the virtual environment for the application of a sense of touch and a sense of temperature degree, for example, they have the ability to find a sense of real environmental conditions.

C) Motion Sensors (Motion Sensing):This technique is essentially a special suit worn by the actor , and put on it white points placed them in the joints sites (such as the wrist, elbows, ankle, knee), and put these points as well as on the head and face, and the pair of video units follow-up the movements of these points (where each point configured via special software program, and there is similar points linked it with the virtual character is designed in the computer, and through the powerful computer processors and complex software, virtual character is animated with a very realistic movement using different shots which it is recorded by the real actor, this process is 
known as stirring Performance Animation and In some applications it is simulated the actor's head and face movement and even his eyes and his mouth movement through a virtual character speaking.

The aim of stirring Performance Animation is achieved fast and accurate construction of the character in the virtual world, and this method has recently used in the production of many films such as: 0 . J. Simpson which contained stirring Performance Animation of what supposed had happened at the crime scene.

D) Multi- directions telescope (BOOM): Multi- directions telescope (BOOM) is developed by Fake space. it is consist of screens, and projector system combined in a box jointed with multiconnections 'arm, and when the user look through the slots in the box, he can see the virtual world, and he can direct the box in any direction that the existing processing capacity in the tool is allowing it, and the process of following the head's movement track via Sensors in the arm's connections that hold the box.

E) The Automatic Virtual Environment CAVE :The Automatic Virtual Environment CAVE is developed in the Illinois University of American Chicago State, which gives inspiration of immersion via displaying stereoscopic images on the walls and a cube land fitted the size of a room, and a number of people who wear stereoscopic glasses can enter and goal freely inside the cave, and The tracking system of head's movements is continuously adjust the stereoscopic display process according to the position where the Advanced beholder looks at it.

F) Assistive devices :Assistive devices vary in the virtual reality, For example: control rod, mouse and keyboard. In general, the input devices for virtual reality programs are continuously developing. As it appear recently in the markets Assistive devices, such as: track ball, tri-dimensional control stick, movement stick and the butt head, etc., and all are Assistive devices for virtual reality applications.

E) The computer system:There is no doubt that the virtual reality is mainly depends on the computer device, but (to reach to the full sense of virtual reality as the reality, it must be a high specification computer system is generated geometric shapes in a distinctive way which describes the data and information technically and wonderfully similar to virtual reality.

G) Nano Manipulator device or nanometer processor (Nano Manipulator(: Nano Manipulator includes a pointing machine looks like a driving cars' stick, this machine conducts to a personal computer provided with very advanced graph card, it convert the microscope data for exposure in the form of a three-dimensional image of multiple colors, this sensor enables scientists to touch and feel the sights of small things that they examine it and scientists have felt with the small edges and gaps existed in the protein molecules, and viscosity of some types of pathogenic bacteria.

The most advanced version of Nano Manipulator is in the Department of Physics at the North Carolina University at "Chapel Hill". And for the severe importance of this 
device in many researches of researchers at other institutions, the researchers of computer science at the North Carolina University made a study to make this device accessible to everyone. And "Kevin Gievaa" ,professor of computer science tried to use the second generation technology of the Internet, which his success will lead to using it for allowing researchers to send samples and checked it remotely using the Internet. This researcher has already been doing practical expert through examining a sample in University the capital Washington, 270 miles from the place of examination at the North Carolina University, but this expert had some problems.

H) Virtual worlds, for example (Second Life world):Internet is also one of virtual reality tools, via multiple ways, one of these methods is the virtual world, and the Second Life is an example of the virtual world. And (Second Life is a virtual game, it required a fast internet connection and a PC with high specifications to be able to run, her idea spins about making a virtual character for you and then enter a virtual world that resembles the world in which we live, you can walk around there freely, and build many friendships, you can chat Using text, audio and even video, as you can buy your own house, or start trading there, through this world currency called Lidden ..).And some of the players spend between 4 to 10 hours a day on this game and some of them feel too immersive in the game to see some of the installations and the scenes that you may see in the reality.

Installing virtual education platform provided with video hologram call \&video conferences \&chats with professors and students or with each other

Video conference between the professor \& his students or between professors with each other or with experts and also between students with each other or with experts

Generated hologram objects for education purposes

Generating virtual reality education environments \& Simulation the real environments used for education purposes.

These environments provide with three points including : immersion, practice, test. And this is the Standards of good virtual reality environment.

Abdul Hamid (2003) Said that we really live in an imaginary world, many events around us are imaginary.

Cinema, theater, drama and databases, even mental images composed in the memory, also it has been imaginary, but we don't consider all of that imaginary virtual reality environments, because virtual reality environments should be provided by the following characteristics \& considerations:

Honestly simulated: where you must represent and simulate the real virtual reality environment actually honest representation \& simulation. 
Interactive Immersion \& integration. As the teacher doesn't interact with the virtual reality from the outside, but he indulges in it and become integrated and completed part of it.

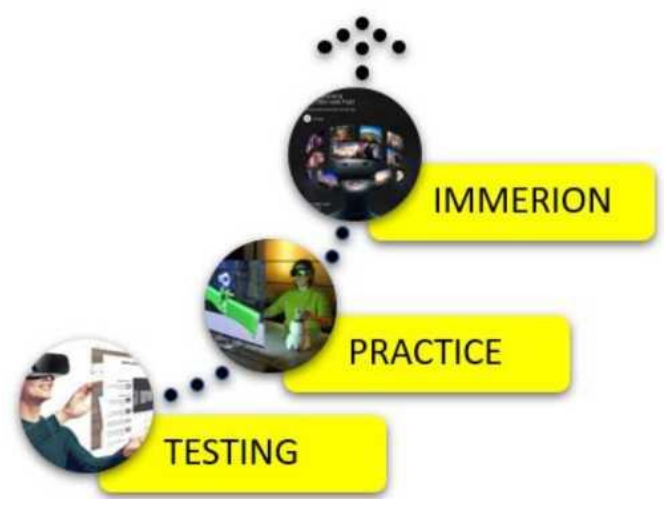

The embodiment of personal Avatar: it is an animated puppet generated by computer, represented the user inside the virtual reality environment, and embodies the idea in the user person.

The disappearance of the interaction interface within the environment: because the user doesn't interact with the environment from the outside, but he is an integrated part of it, so there is no need for him to the external interaction interface, where it disappears within the environment itself, so that the user interacts directly with the virtual reality in the moment.

\section{D \& Hologram Power point}

Dr. Sengupta - The Winner in Contributors Competitions of Arther . Ai .Wiman For Youth Organized By echocardiography Association Introduced 3d Power Point for the First Time with hologram communication call , and Images Up To 8 Ft High in 2013
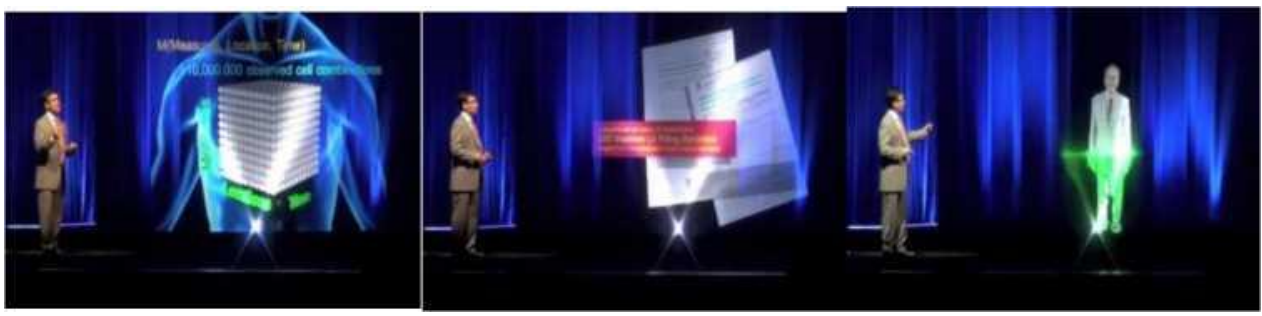

Several Images Up To $8 \mathrm{Ft}$ High for Dr.Sengupta Introduced 3d Power Point for the First Time And making hologram communication call, in 2013

The golden pyramid- as the researcher caller this name on it-for installing virtual university education platform depending on three integrated elements in their role they are the innovator, programmer, and designer. 


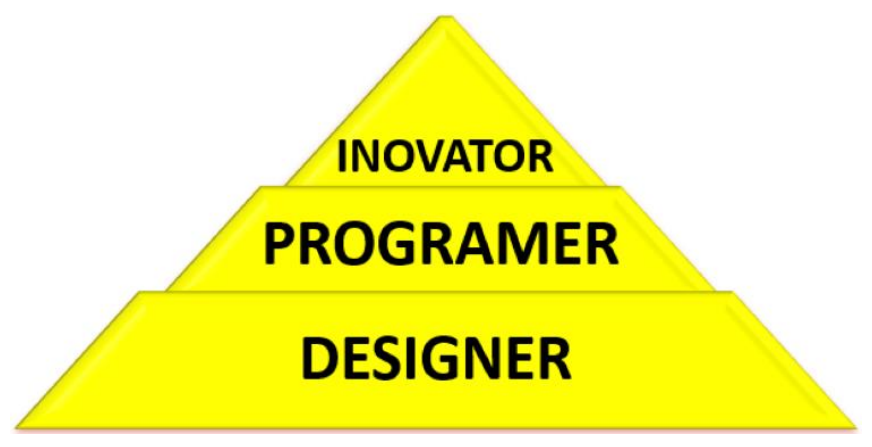

A graph of the golden pyramid- as the researcher called this name on it-for installing virtual university education platform depending on three integrated elements in they role .they are the innovator,programmer, and designer

\section{The Concept of Virtual University}

Virtual University can be defined procedurally traditional school in the presence of teachers, students and administrative \& educational corps, but on the World Wide Web (Internet) where it isn't bound by time or place, and based on multiple global Web technologies ,like: discussion ,conferences and forums, and reading lessons, and perform the duties .., and etc.

Virtual University is an academic institution aimed at securing the highest levels of higher education for students in their places of residence mediated by the World Wide Web through the establishment of an integrated e-learning environment based on a sophisticated network, "the first virtual integrated and accepted university has been established to provide more than 600 study material on the Internet, called the Jotr University in Denver, Colorado and its website (www.jonesknowledg.com) .

Virtual lectures are the tools, techniques, and software on the World Wide Web "Internet" enables the teacher to disseminate lessons and objectives and put duties and tasks of study and communicate with his students via multiple technologies, as it enables the student to read goals and tutorials and solving homework and sending tasks and participation in the discussion areas and dialogue and see his progress in studying and his degree obtained" .

\section{Integration Cycle Process of Virtual University Education Via Multimedia}

It is described the integration communication between the professor -who developed the virtual education process with both e-learning \& e-training - and his students who are different types in realizing via professor's visalization or listening tools or both together , as follows: 


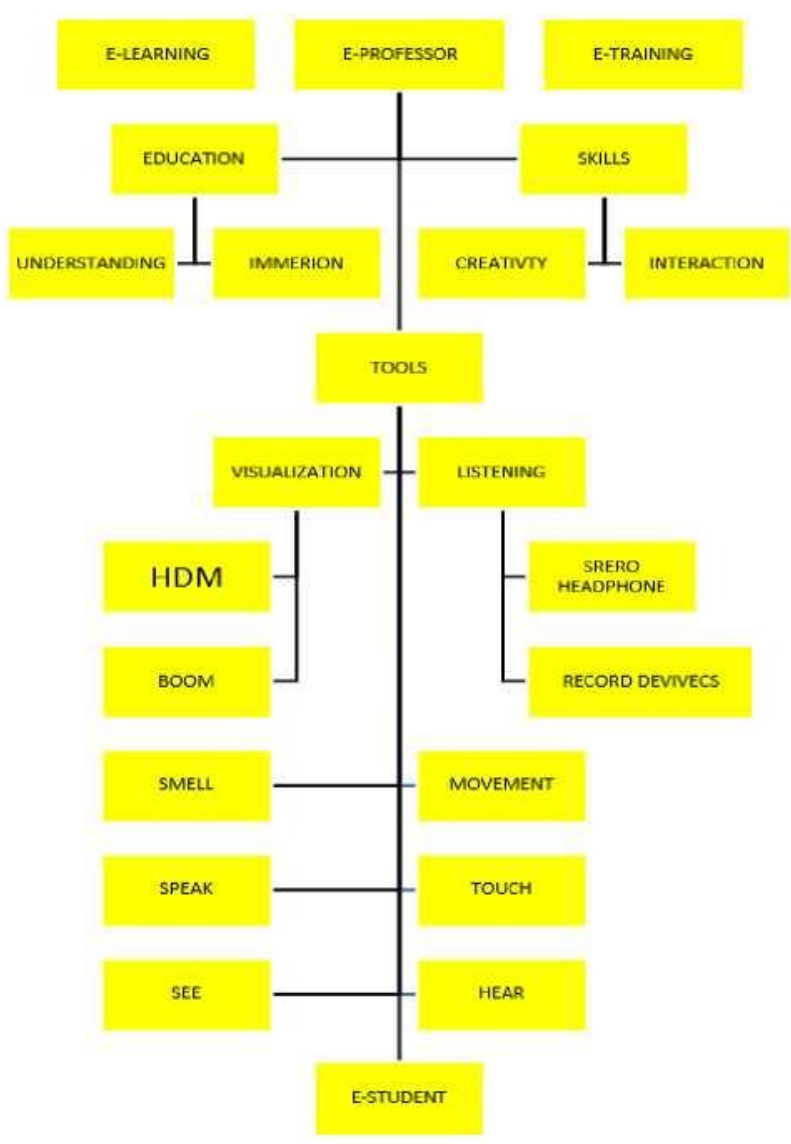

A graph of integration cycle of virtual education via multimedia

\section{Integration Cycle of Virtual Education Via the Reality Simulation}

As it describes immersion virtual reality\&semi -immersion virtual reality \& non immersion virtual reality, as follows:

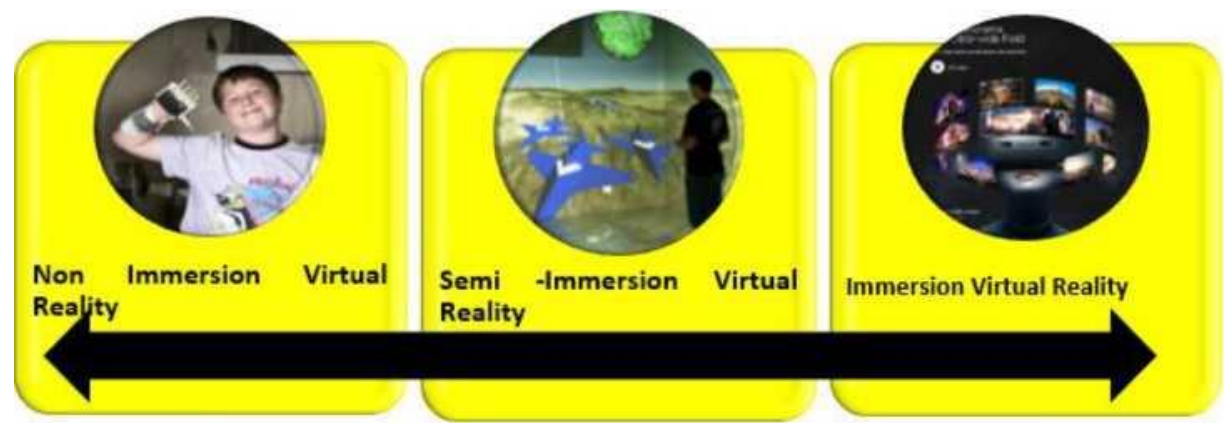

A graph of integration cycle of virtual education via the reality simulation 
The models of these virtual universities on the World Wide Web (Internet) are the following examples:

\section{(Phoenix)University}

This is one of the largest private universities in America, where there is 440,000 students), students - studying through the Internet at this university - represents $10 \%$ approximately of students number (4,000 students), this university accepted only students' ages at least 23 year (the class of society that missed university education) ,also it requires that the student is an employee, as the university does not contain staff working regularly, or even libraries, so the faculty has been rent - rather than buy - temporary substitutes in about 10 US states.

As the curriculum focuses on information technology, education, and health, and it is the pioneer faculty in introducing study materials online. The university offers (800) class in (5) Diploma programs and (5) other BS, and a number of faculty members contracted with them to work at the university through the Internet. Internet's students in the university represent equivalent to $(10 \%)$ of the total students.

\section{Syrian Virtual University:www.svuonline.org/Arab.SVU/index.asp}

Syrian Virtual University is the first integrated virtual university in the Middle East, which leads the education movement on the Internet in the region. It puts on the web new educational methods based on international standards, and of modern manifestation techniques of advanced and exciting experience of the learning process.

It is currently coordinating as it puts between the student's hands the most important US, European and global universities. The Syrian Virtual University provides student with the highest virtual environment to facilitate their rich interaction with their professors, friends. and technologies around the world. It also it provides them with an academic, technical and administrative support of the most important experts, scholars and professors of Arab origin and a global study.

\section{The results and recommendations to overcome the challenges of research:}

The virtual reality environment technology is one of the growing technologies and some time will spend on the adoption of desktop computers for this environment due to halt the spread of this technology to provide supporting for her in various operating systems, and unsuitability for applications used in this type of computers, but Intel company solved this problem by dealing with programs' companies to provide support for her in their programs without relying on the support of the operating system. The software and operating systems developers adopt this technology in addition to companies specialized in producing computer hardware components such as IBM and AMD.

On the other hand (after «MTV» becomes one of the most famous names in the world of television networks, it is now trying to enhance its successes to become a leader in the marketing of virtual worlds. This was her message of this giant network through 
the virtual worlds conference in 2007 which held in New York. And this net launched her strategy of new hybrid network platform«4D», or four dimensions.

The primary endeavor of this will be the focus on the integration of existing content in television programs in «MTV» networks, with three-dimensional virtual worlds, and then it will place them within an interactive circle so that persons can interact through it with television characters and producing new content, his role is being a part of experience shared by everyone.

\section{Recommendations to overcome the teacher resistance to change in the university education level}

Teaching in a virtual classroom isn't intended to record a traditional separation and put it on the Internet in order to bring the students practically, it isn't intended to record, and write it in the text and then published it in a Web page. But it is intended to transfer the assets of traditional education science towards electronic science pedagogy in which the professor becomes a facilitator of student learning and proactive education pedagogy. It assumed the "new" education science assets that the teacher must qualify in the new educational technologies, but also that he must be left, in whole or in part, to face-to-face interaction in the classroom, and for some of them, this is very difficult.

\section{To overcome the resistance of students to work without a "teacher" in front of them}

Our students are used to working in a classroom in which Professor speaks only directs his classroom. This makes students adopt a negative attitude (based on listening to the teacher); In this case, a good teacher who is making every effort, while the bad teacher has large demands, the teacher who works instead of his students and who doesn't give everything.

The result is that a huge distrust was born about the easy teacher role, where the professor's site is in the virtual class, but, at the same time, the responsible site that generates resistance to leave laziness and ease. The one professor who plays the role of "Father" as he has all knowledge (the only) and all power (to direct his students to where he wants) .

It is the site generates a lot of satisfaction because of the power of recognition and discrimination and admiration that appears in many times, but at the same time is the site prevents the diversity of ideas, and promotes iterative learning and kills creativity. so the professor should protect student laziness as in his role can rest in peace without forcing to think , and just only pushing to save information for tests and examinations, and save information of the content which he received in the class, and there isn't in other research, or what the student reads or encountered more than what is required from him. 


\section{To overcome the legal, administrative and technical barriers}

\section{For technical obstacle:}

To apply the techniques those allow us to apply virtual education. We must provide several devices (computers connected to the Internet) for students who attend half virtual classes, and also virtual support classes, and those who don't have computers and Internet connection at home, this also requires a data transfer rate larger so as not to break down the network. If all students entered the virtual classroom at one time . As More computers, the largest data transfer rate, which means the quality of education is better, which attracts more students (including students' long distances).

\section{References}

\section{Arabic References}

[1] Marwa Ahmed Yousef Al-Sharif, animation employment and multimedia technology in the production of an entertaining educational site, unpublished Master Thesis, 2011.

[2] El-husary, Ahmed (2000): the Education Technology in reality and hope school system, the Seventh Annual Scientific Conference of the Egyptian assosciate for Education Technology, fulfillment house , Mansoura.

[3] El-garib, Zaher Ismail (2001): Information technology and modernization of education, the world of the book, Cairo.

[4] El-Mousa, Abdullah Abdul-Aziz and Al-Mubarak, Ahmed Abdulaziz (2005): Elearning principles and application, Data Network Foundation, Riyad

[5] El-Sharhan, Gamal (2006): E-book and e-school and virtual teacher, print2, Riyadh

[6] Mhaisni Ibrahim ,Hashem, and Khadija bent Hussein (1423) E-school is the Future School", a study of concepts and models" worksheet submitted to the School of the Future Symposium, King Saud University, College of Education

[7] EL-Arini, Abdul Rahman (1423) of programmING instruction to e-Learning, Knowledge Magazine, Issue 91 SHAWAL 1423 ,r December 2003

[8] Martin, Chuck (1999): the Internet future, translation of Moses Younis, International House ideas /El-Riyad.

[9] Levy, p (1997) quest-ce que le virtuel? Paris : la Decouverte 